\title{
Rare arch and supra-aortic vessel anomaly
}

\author{
Gustavo Cortez, Pedro Aguilar-Salinas, Roberta Santos, Ricardo A Hanel
}

Lyerly Neurosurgery, Baptist Neurological Institute, Jacksonville, Florida, USA

\section{Correspondence to} Dr Ricardo A Hanel, rhanel@|yerlyneuro.com

Accepted 18 September 2017

\section{DESCRIPTION}

A 3-year-old child with history of a large secundum atrial septal defect came to our institution for surgical cardiovascular evaluation. The patient had reached all developmental milestones and was completely asymptomatic. During imaging workup, a three-dimensional magnetic resonance angiography (MRA) reconstruction showed an incidental finding of a unique left aortic arch with branch vessel anomalies. The images showed a fenestrated origin of the left common carotid artery (figure 1A) along with an independent origin of the right internal and external carotid arteries from the brachiocephalic trunk, with a partial fusion in their proximal segments (figure 1B). At the time of diagnosis, neurology and neurosurgery services were consulted suggesting only close monitoring. At the 6-month follow-up, the patient remains neurologically intact.

Anomalies of the aortic arch are usually associated with impaired development of the branchial arches, heart defects and chromosome abnormalities. Although most of the anomalies are silent, vascular variations may produce respiratory and
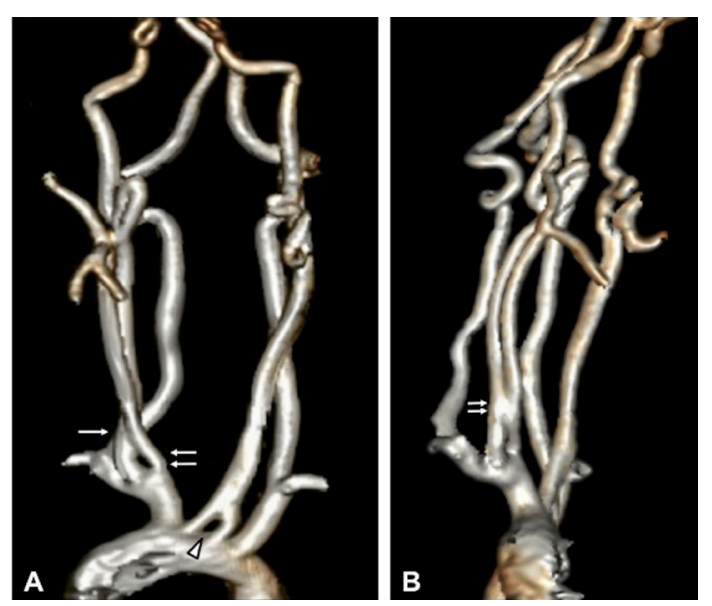

Figure 1 Three-dimensional magnetic resonance angiography reconstruction. (A) Anterior view depicting the fenestrated origin of the left common carotid artery (arrowhead), the independent origin of the internal carotid (single arrow) and external carotid (double arrows) arteries. (B) Right lateral view demonstrating partial fusion of the proximal segments between right internal and external carotid arteries.

\section{Learning points}

- Aortic arch anomalies are associated with impaired development of branchial arches, heart defects and chromosome abnormalities.

- These anomalies are usually clinically silent and commonly found as an incidental finding on imaging studies.

- Thorough imaging evaluation is fundamental to determine the vascular configuration and guide the treatment strategy.

cardiovascular symptoms. Thorough imaging evaluation is fundamental to determine the vascular configuration and guide the treatment strategy. ${ }^{12}$

Cardiovascular imaging evaluation includes non-invasive studies such as echocardiogram, CT and MRI reconstructions. MRA is a feasible option in paediatric patients since it allows reconstruction of the vessels without exposing the patient to ionising radiation or contrast. Moreover, when associated with congenital cardiac anomalies, MRI has the advantage to provide additional information on ventricular function and blood flow. ${ }^{2}$ Clinical silent aortic arch anomalies are incidental findings, occasionally discovered during cardiac evaluation.

Acknowledgements RS is sponsored by the Interline Endowment Grant.

Contributors GC, PAS and RS were responsible for the study concept and design and contributed to drafting of the manuscript. GC contributed to acquisition of the data. RAH contributed to study supervision and critical revision of the manuscript for important intellectual content. All the authors were responsible for analysis and interpretation of the data, administrative, technical and material support

Competing interests RAH is a consultant for Stryker, Codman, Covidien, and MicroVention. The remaining authors have nothing to disclose.

Patient consent Obtained

Provenance and peer review Not commissioned; externally peer reviewed.

(c) BMJ Publishing Group Ltd (unless otherwise stated in the text of the article) 2017. All rights reserved. No commercial use is permitted unless otherwise expressly granted.

\section{REFERENCES}

1 Hanneman K, Newman B, Chan F. Congenital variants and anomalies of the aortic Aarch. Radiographics 2017;37:32-51.

2 Kellenberger CJ. Aortic arch malformations. Pediatr Radiol 2010;40:876-84. 
Copyright 2017 BMJ Publishing Group. All rights reserved. For permission to reuse any of this content visit http://group.bmj.com/group/rights-licensing/permissions.

BMJ Case Report Fellows may re-use this article for personal use and teaching without any further permission.

Become a Fellow of BMJ Case Reports today and you can:

- Submit as many cases as you like

- Enjoy fast sympathetic peer review and rapid publication of accepted articles

Access all the published articles

- Re-use any of the published material for personal use and teaching without further permission

For information on Institutional Fellowships contact consortiasales@bmjgroup.com

Visit casereports.bmj.com for more articles like this and to become a Fellow 